\title{
CONDIÇÕES FÍSICAS E HIGIÊNICO-SANITÁRIAS DO ABATE CLANDESTINO EM UM MUNICÍPIO DE ALAGOAS, NORDESTE BRASILEIRO
}

\author{
Hellen Tenório BEZERRA ${ }^{\mathbf{1}}$; José Andreey Almeida TELES ${ }^{\mathbf{2}}$; Gil Dutra FURTADO ${ }^{3 *}$
}

\author{
${ }^{1}$ Pós-graduanda em Gestão da Segurança Alimentar e Vigilância Sanitária/ Faculdade Integrada de Patos \\ (Posfip), Patos, Paraíba, Brasil. \\ ${ }^{2}$ Mestre em Biociência Animal, Médico Veterinário, Professor/Centro Universitário Maurício de Nassau \\ (UNINASSAU), João Pessoa, Paraíba, Brasil. \\ ${ }^{3}$ Graduando em Medicina Veterinária/Centro Universitário Maurício de Nassau (UNINASSAU), João Pessoa, \\ Paraíba; Agrônomo/Universidade Federal da Paraíba (UFPB); Doutor em Psicobiologia/Universidade Federal do \\ Rio Grande do Norte (UFRN); Agrônomo-Sócio da Cooperativa do Agronegócio (COOPAGRO), Natal, Rio \\ Grande do Norte, Brasil. \\ *Autor para correspondência. E-mail: gdfurtado@ hotmail.com
}

Resumo. O Brasil é líder em exportações e dono do segundo maior rebanho mundial, com cerca de 200 milhões de cabeças de gado. Mesmo apresentando números elevados referentes à produção de produtos cárneos, o país sofre com a clandestinidade no abate de bovinos. Além disso, o consumo de carne ou subprodutos contaminados pode ser a causa de diversas doenças graves. Essas doenças só podem ser devidamente identificadas mediante a inspeção ante e post-mortem às quais os animais são submetidos no matadouro legalizado, procedimento que não ocorre em abates clandestinos. Diante disso, objetivou-se realizar uma análise das condições físicas e higiênico-sanitárias do abate clandestino em um município de Alagoas bem como, sua implicação na saúde pública. Foram realizadas visitas durante o período de junho a julho de 2019, com abate semanal médio de dez animais sendo observados condições das instalações, higiene do local e dos manipuladores, procedimento de matança, uso de equipamentos, forma de abate até o transporte e destino do produto final. Durante a visita ao abatedouro foi observado que no local do abate não tinha nenhum tipo de adequação para o fim a que se destinava, pois não existia nenhum tipo de instalações físicas acontecendo ao ar-livre e favorecendo assim a proliferação de micro-organismos. As pessoas envolvidas não utilizavam EPI's durante as etapas de abate dos animais. A esfola aérea não era utilizada em nenhum dos animais, devido à inexistência de trilhos aéreos, sendo realizada diretamente no solo, propiciando a contaminação da carcaça. As vísceras eram lavadas em tonéis e baldes de água, manipuladas em cima de lonas e sacos de estopas sendo enxugadas com auxílio de um pano de prato, em precárias condições de higiene. As carnes eram expostas em ganchos facilitando a retirada das pelancas ao ar-livre e à temperatura ambiente, até serem recolhidas e transportadas na mala de carros particulares, carrocinhas e carroceria de caminhão até o mercado e açougues da região, sem refrigeração e condições precárias de armazenamento. Concluiu-se que as condições físicas e 
higiênico-sanitárias são inexistentes para a finalidade que se destinam, pondo em risco a saúde do manipulador e da população.

Palavras-chave: Clandestinidade; Abatedouro; Bovinos; Carne.

\section{PHYSICAL AND HYGIENIC-SANITARY CANDITIONS OF CLANDESTINE SLAUGHTER IN A MUNICIPALITY OF ALAGOAS}

Abstract. Brazil is the leader in exports and owner of the second largest herd in the world, with about 200 million head of cattle. Even with high numbers related to the production of meat products, the country suffers from the illegal slaughter of cattle. In addition, the consumption of contaminated meat or by-products may be the cause of several serious diseases. These diseases can only be properly identified by ante and post-mortem inspection to which the animals are subjected to the legalized slaughterhouse, a procedure that does not occur in clandestine slaughter. Therefore, the objective was to perform an analysis of the physical and hygienic-sanitary conditions of clandestine slaughter in a municipality of Alagoas as well as its implication in public health. Visits were carried out from June to July 2019, with an average weekly slaughter of ten animals, observing the conditions of the premises, the hygiene of the place and the handlers, the killing procedure, the use of equipment, the way of slaughter until the transport and destination of the animals. final product. During the visit to the slaughterhouse it was observed that at the slaughter site there was no suitability for its intended purpose, as there was no type of physical facilities going on outdoors and thus favoring the proliferation of microorganisms. The persons involved did not use PPE during the slaughtering stages of the animals. The skinning was not used in any of the animals, due to the lack of air rails, being performed directly on the ground, providing contamination of the carcass. The viscera were washed in vats and buckets of water, handled on canvas and toweling bags and wiped with a dish towel under poor hygiene conditions. The meats were exposed on hooks facilitating the removal of open-air and room temperature skins until they were collected and transported in the trunk of private cars, vans and truck bodies to the local market and butchers, without refrigeration and poor working conditions storage. It was concluded that physical and hygienic-sanitary conditions are nonexistent for their intended purpose, endangering the health of the handler and the population.

Keywords: Clandestinity; Slaughterhouse; Cattle; Beef.

\section{CONDICIONES FÍSICAS E HIGIÊNICO-SANITÁRIAS ABATE CLANDESTINO EM UM MUNICÍPIO DE ALAGOAS}

Resumen. Brasil es el líder en exportaciones y propietario del segundo rebaño más grande del mundo, con cerca de 200 millones de cabezas de ganado. Incluso con grandes números relacionados con la producción de productos cárnicos, el país sufre la matanza ilegal de ganado. Además, el consumo de carne o subproductos contaminados puede ser la causa de varias enfermedades graves. Estas enfermedades solo pueden identificarse adecuadamente mediante una inspección ante y post mortem a 
la que los animales son sometidos al matadero legalizado, un procedimiento que no ocurre en el sacrificio clandestino. Por lo tanto, el objetivo era realizar un análisis de las condiciones físicas e higiénico-sanitarias de la matanza clandestina en un municipio de Alagoas, así como su implicación en la salud pública. Las visitas se llevaron a cabo de junio a julio de 2019, con un sacrificio semanal promedio de diez animales, observando las condiciones de los locales, la higiene del lugar y los manipuladores, el procedimiento de sacrificio, el uso del equipo, la forma de sacrificio hasta el transporte y destino de los animales como producto final. Durante la visita al matadero se observó que en el lugar del matadero no había idoneidad para el propósito previsto, ya que no había ningún tipo de instalaciones físicas al aire libre que favorecieran la proliferación de microorganismos. Las personas involucradas no usaron EPP durante las etapas de sacrificio de los animales. El desollado no se usó en ninguno de los animales, debido a la falta de rieles aéreos, ya que se realizó directamente en el suelo, lo que contaminó la carcasa. Las vísceras se lavaron en cubas y cubos de agua, se manipularon sobre lienzo y bolsas de toallas y se limpiaron con un paño de cocina en condiciones de higiene deficientes. Las carnes se expusieron en ganchos, lo que facilitó la eliminación de las pieles al aire libre y a temperatura ambiente hasta que se recogieron y transportaron en el maletero de automóviles, camionetas y carrocerías privadas al mercado local y carnicerías, sin refrigeración y almacenamiento en malas condiciones de trabajo. Se concluyó que las condiciones físicas e higiénico-sanitarias son inexistentes para su propósito previsto, poniendo en peligro la salud del manejador y la población.

Palabras clave: Clandestinidad; Matadero; Vacas; Carne de vaca.

\section{INTRODUÇÃO}

O Brasil é líder em exportações e dono do segundo maior rebanho mundial, com cerca de 200 milhões de cabeças de gado. Desde 2004, assumiu a liderança nas exportações, com um quinto da carne comercializada internacionalmente e vendas em mais de 180 países (MAPA, 2013). No $1^{\mathrm{o}}$ trimestre de 2018, foram abatidas 7,72 milhões de cabeças de bovinos sob algum tipo de serviço de inspeção sanitária segundo os dados do IBGE (IBGE, 2018).

Mesmo apresentando números incríveis referentes à produção de produtos cárneos, o país sofre com a clandestinidade no abate de bovinos, pois, de acordo com Rouquayrol e Almeida Filho (2003), a maior parte dos municípios brasileiros não desenvolve ações de inspeção dos produtos de origem animal, nem dispõe de condições adequadas de abate.

De acordo com a Lei Federal $n^{\circ} 8.137 / 90$, o abate clandestino é uma atividade ilícita considerada crime contra as relações de consumo. E, apesar da existência de leis que regulam os serviços de inspeção e vigilância sanitária, a fim de coibir estes abatedouros e melhorar a situação da carne comercializada no Brasil, a perpetuação destes estabelecimentos, continua sendo um grave problema na saúde pública nacional por décadas. Bánkuti (2001) cita que a 
clandestinidade possui duas condições básicas: a não fiscalização pelo serviço de inspeção sanitária e a sonegação fiscal.

Além da questão sanitária, o abate clandestino envolve ainda a questão ambiental, pois geralmente é realizado em locais próximos a rios ou córregos para facilitar a captação de água. Todavia, sangue e restos de animais acabam sendo despejados nessas águas ou ainda consumidos por animais próximos ao ponto de abate, aumentando o risco de disseminação de doenças (COSTA et al., 2011).

As doenças zoonóticas são aquelas transmitidas dos animais para o ser humano, estão espalhadas no mundo de acordo com as diversas alterações ambientais, socioeconômicas e culturais. Os casos vêm aumentando gradualmente devido às constantes modificações causadas pelo o homem no ambiente, na maioria das vezes, os casos de doenças estão em regiões onde as populações são carentes, possui hábitos precários de higiene e baixa renda, propiciando um espaço maior para a infecção por agentes patogênicos (LIMA et al., 2017).

A transmissão destas doenças podem ocorrer de diversas formas, dentre elas, manipulação de carcaça animal e de vísceras contaminadas, além de sangue, urina, fezes e material perfuro-cortante durantes as etapas no momento do abate (TAVOLARO et al., 2007).

O aumento da produtividade na criação de animais, muitas vezes envolve a uso de centenas de substâncias utilizados como princípios ativos em produtos para a saúde e tratamento de animais produtores de alimentos. De acordo com isso, muitos dos animais são expostos a químicos que podem deixar resíduos na carcaça no momento do abate (VRAGOVIC et al., 2011).

O uso incorreto de antibióticos em veterinária podem deixar resíduos nos produtos de origem animal. Estes resíduos podem ter efeitos tóxicos diretos sobre os consumidores, por exemplo, reações alérgicas em indivíduos hipersensíveis, ou podem causar problemas indiretamente através da indução de cepas resistentes de bactérias (STOLKER \& BRINKMAN, 2005).

O consumo de carne ou subprodutos contaminados pode ser a causa de diversas doenças graves, como: Tuberculose, Cisticercose, Carbúnculo Hemático, Listeriose, Estreptococose, Toxoplasmose, Mormo, Yersinose, Intoxicações estafilocócicas e alimentares, Salmoneloses, entre outras. Essas doenças só podem ser devidamente identificadas mediante a inspeção ante-mortem e post-mortem às quais os animais são submetidos no matadouro legalizado, procedimento que não ocorre em abates clandestinos (COSTA et al., 2011). Diante disso, esta pesquisa teve como 
objetivo realizar uma análise das condições físicas e higiênicas-sanitárias do abate clandestino no interior de Alagoas bem como sua implicação com a saúde pública e justifica-se a publicação deste por entender que o meio acadêmico não pode se omitir perante aos grandes prejuízos que este mercado traz à população de forma geral.

\section{METODOLOGIA}

O presente trabalho foi realizado em um abatedouro clandestino localizado em um município no interior de Alagoas. As visitas foram realizadas durante o período de junho à julho de 2019, com abate semanal médio de dez animais.

As visitas foram realizadas durante os abates onde foi observado a situação das instalações e os procedimentos de abate dos animais, bem como a utilização de equipamentos de proteção de uso individual (EPI’s) sendo realizadacom autorização dos proprietários, sob a condição de total sigilo quanto à identificação dos mesmos e dos endereços.

Ainda assim, foi realizado aos responsáveis pelo local uma entrevista sobre a classificação física, higiênica e sanitária, contendo informações das condições das instalações, higiene do local e dos manipuladores, procedimento de matança, uso de equipamentos, forma de abate até otransporte edestino do produto final.

\section{RESULTADOS E DISCUSSÕES}

Durante a visita ao abatedouro foi observado que no local do abate não tinha nenhum tipo de adequação para o fim a que se destina pois não existia nenhum tipo de instalações físicas como piso ou paredes acontecendo ao ar-livree favorecendo assim a proliferação de microorganismos.

As pessoas envolvidas no abate dos animais em todas as etapas não faziam uso de EPI’s mínimos (Figura 1), como máscaras, luvas e botas, aumentando o risco do contato direto das superfícies mucosas com respingos de sangue, fezes, urina, além de acidentes com materiais perfuro-cortantes possivelmente contaminados. De acordo com a legislação (BRASIL, 2008), os estabelecimentos devem dispor de rouparia, vestiários, banheiros, privadas, mictórios e demais dependências necessárias, em número proporcional ao pessoal, instaladas separadamente para cada sexo, completamente isolados e afastados das dependências onde são beneficiados produtos destinados à alimentação humana. 
Figura 1: Manipuladores com ausência do uso de equipamentos de proteção individual (EPI’S).

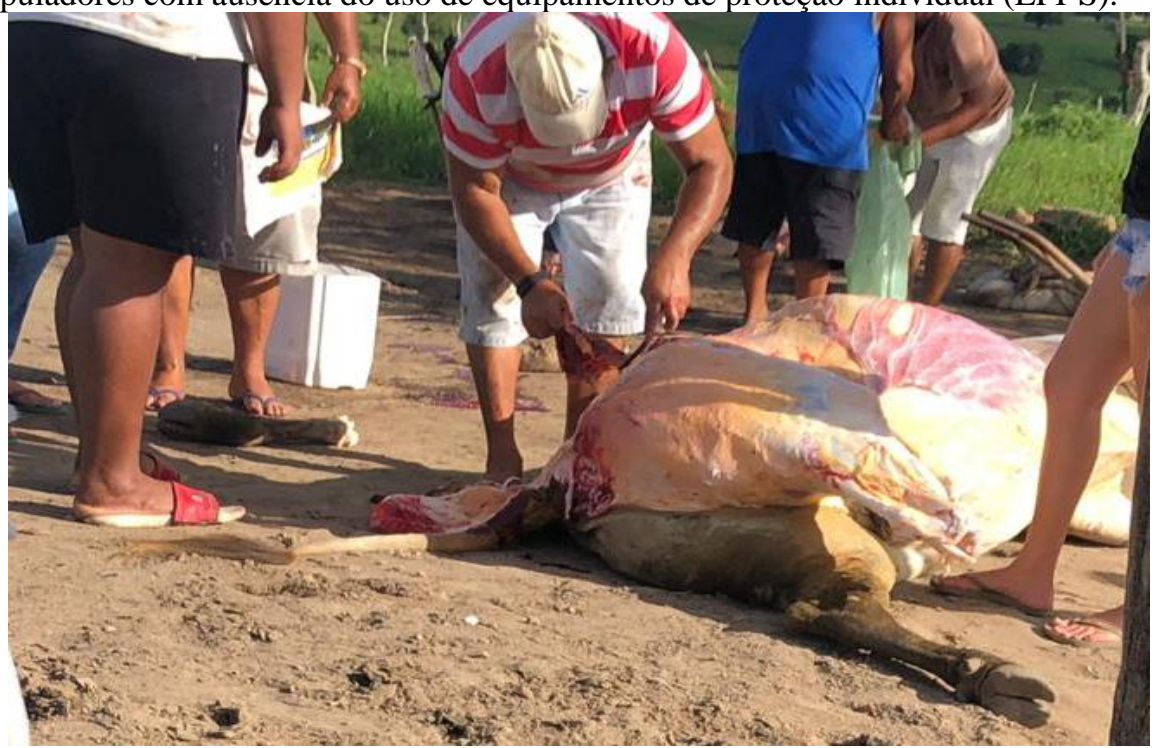

Fonte: Dados da pesquisa, 2019.

Os animais eram trazidos de fazendas vizinhas e ficavam em um único curral esperando o abate sem nenhum tipo de descanso, jejum hídrico ou alimentar. O jejum alimentar tem por objetivo diminuir a contaminação com resíduos alimentares ou intestinais, evitando que carcaças sejam desperdiçadas, e melhorar a eficiência na produção (DUKEet al., 1997; NORTHCUTT et al., 1997; SAVAGE, 1998).

Dentre os fatores que antecedem o abate, o período de jejum de ração é o mais importante, pois pode evitar contaminações e prejuízos nos rendimentos das carcaças caso seja feito de maneira correta. Além disso, o jejum pré-abate pode reduzir os efeitos do estresse calórico e diminuir os riscos de contaminações de carcaças por rompimento de vísceras no abatedouro (SCHETTINO et al., 2006).

A movimentação dos animais era feita com material inadequado pontiagudo e corda. A condução dos animais até a linha de abate deve ser executada de maneira o menos estressante possível, isso será atingido levando-se em consideração os aspectos construtivos das instalações (PEREIRA; LOPES, 2006). Outro fator importante é quanto à presença de pontos metálicos que possam provocar reflexos, ou ruídos de alta intensidade, pessoas ao redor, locais escuros podem representar barreiras que afetarão o avanço normal dos animais pela linha de abate (BARBOSA FILHO; SILVA, 2004).

Os animais não passavam por banho antes do abate e também por nenhum tipo de inspeção sobre ectoparasitas ou ainda, qualquer tipo de tratamento à base de medicamentos sendo um risco a saúde do consumidor. Segundo ROÇA (2001), este banho não interfere na sangria, mas serve para a limpeza do couro, evitando contaminação do ambiente e carcaça.

O boxe de atordoamento estava 
ausente, sendo o animal abatido ao lado do curral, na maioria das vezes contido com cordas, aumentando o estresse e contusão do animal, além de favorecer a ocorrência de acidentes com as pessoas do local. O método de abate se dava com o uso de machado para a insensibilização dos animais seguida da sangria onde era rapidamente seccionada a veia jugular com uma faca e o sangue sendo escorrido diretamente sobre um balde e colocado dentro de um tonel.

A esfola aérea não era utilizada em nenhum dos animais, devido à inexistência de trilhos aéreos, sendo realizada diretamente no solo, propiciando a contaminação da carcaça (Figura 2 e 3). Segundo Terra \& Fries (2000), durante o processo de abate, a esfola e a evisceração são considerados pontos críticos de controle que poderão determinar uma maior ou menor contaminação das carcaças. A carcaça inevitavelmente entra em contato com o couro, patas, pêlos, utensílios (facas), equipamentos, manipuladores, uniformes, água de lavagem e com o ar do abatedouro.

As vísceras eram lavadas em toneis e baldes de água e manipuladas em cima de lonas e sacos de estopas sendo enxugadas com o auxílio de um pano de prato ainda sim em precárias condições de higiene e limpeza. As carnes ficavam expostas em ganchos para facilitar a retirada das pelancas ao ar-livre e à temperatura ambiente, até serem recolhidas e transportadas na mala de carro particulares, carrocinhas e carroceria do caminhão até o mercado e açougues da região sobre nenhum tipo de refrigeração e condições precárias de armazenamento. Estes resultados são similares aos que foram observados por FREITAS et al. (2006), onde as condições higiênicas eram mínimas para atordoamento, sangria e evisceração dos animais que eram, na maioria dos locais, realizadas diretamente no solo ou no piso cimentado. Segundo BRASIL (2008), só é permitido o sacrifício de animais de açougue por métodos humanitários, utilizando prévia insensibilização baseada em princípios científicos, seguida de imediata sangria. 
Figura 2: Processo de esfola realizado diretamente sobre o solo.

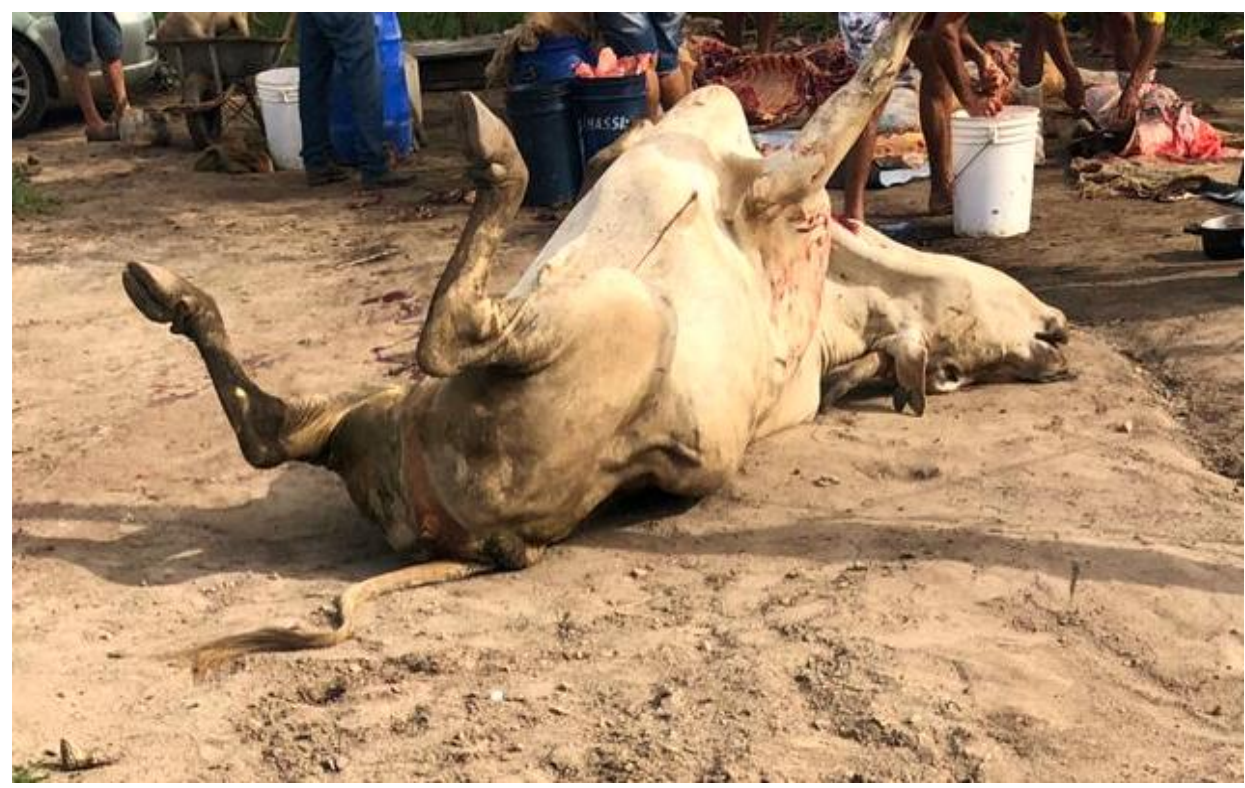

Fonte: Dados da pesquisa, 2019.

Figura 3: Retirada do couro e vísceras sobre lonas e sacos de estopa.

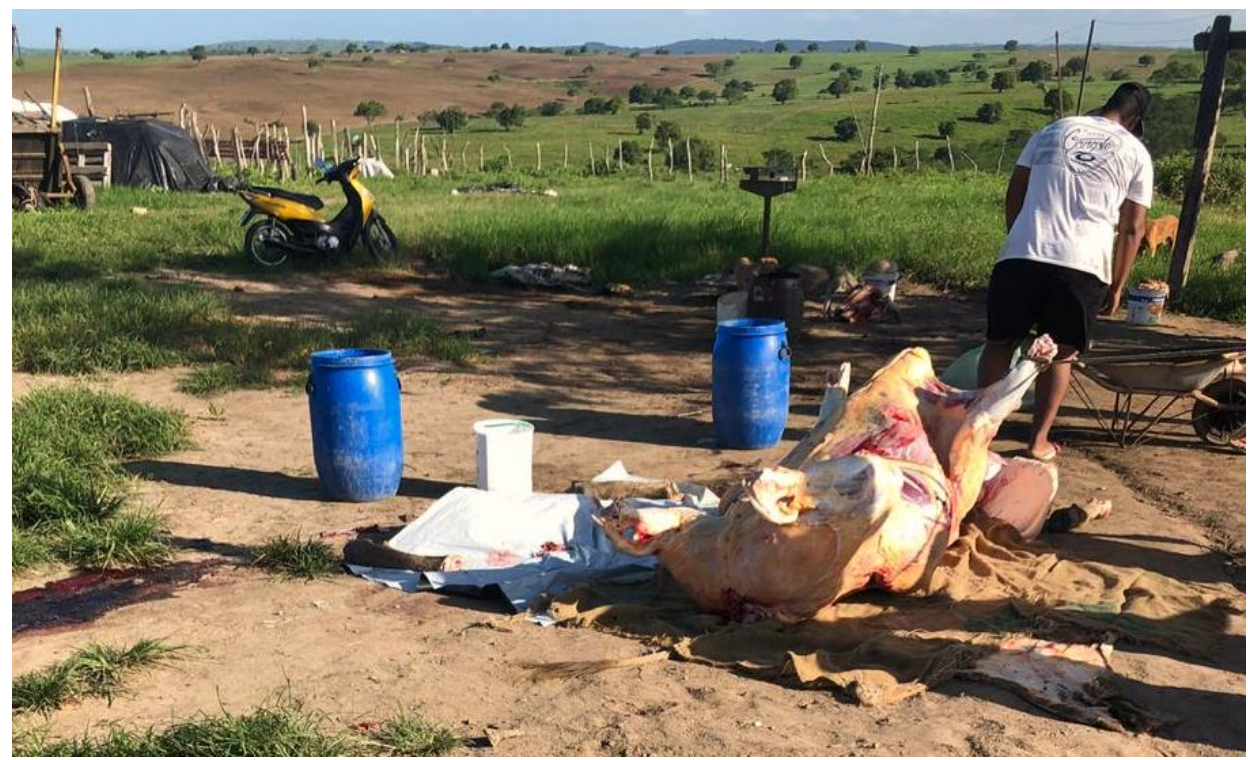

Fonte: Dados da pesquisa, 2019.

O abastecimento de água era feito por um poço e colocado em toneis de água sem passar por nenhum tipo de tratamento ou exame microbiológico antes de ser utilizada. Discordando com BRASIL (2008), onde diz que a água de abastecimento deve ser potável, e quando apresentar mais de 500 micro-organismos/mL deverá passar por outra análise confirmatória antes de condená-la.

Os resíduos não sofriam tratamento e eram despejados a céu aberto. De acordo com SCHOENHALS (2006) nos matadouros e frigoríficos, os efluentes são gerados em grande quantidade e representam um problema sério pelo seu alto teor de matéria orgânica e o 
lançamento desses despejos in natura acarreta sérios prejuízos ao meio ambiente.

Foi comum a presença de cães no local transitando livremente entre os animais abatidos e se alimentando do sangue e de restos de material do abate. De acordo com, BATISTA et al. (2004), estudando a soro prevalência de leptospiras em cães errantes na Cidade de Patos, Paraíba, segundo eles isso sugere o possível contato dos cães com tecidos provenientes de animais infectados abatidos. O lixo não estava devidamente acondicionado, muitas vezes ficando acumulado, a céu aberto. Semelhante ao relatado por FREITAS et al. (2006), que também observaram que o abate era realizado a céu aberto, nos casos extremos em fundo de quintal, onde se amontoam lixo, restos de materiais inservíveis, lama e valas de escoamento de água pluviais. Segundo BRASIL (2008), os estabelecimentos devem ser mantidos livres de moscas, mosquitos, baratas, ratos, camundongos, quaisquer outros insetos ou animais.

Além da inadequada condição higiênica encontrada nolocal, o descaso com a saúde e proteção das pessoas envolvidas nesta atividade e da falta de inspeção sanitária das carnes e carcaças, o bem-estar animal também é outro ponto ausente nestas matanças, uma vez que foge totalmente à legislação, segundo a Instrução Normativa No 3, de 17 de janeiro de 2000, que versa sobre os métodos de insensibilização para o abate humanitário. O que foi observado é que se promoveram maus tratos dos animais desde o seu transporte até o momento do abate, causando stress, afetando diretamente a qualidade da carne (DALLA COSTA, 2007; LIMA; BARBOSA FILHO, 2013).

Sabe-se que a carne, mesmo que seja obtida de animais sadios, é um veículo potencial de contaminantes de natureza biológica, física e química, nas diversas fases de processamento, que vão desde a produção, transformação, armazenamento, transporte e condições de comercialização. Portanto, a carne pode ser contaminada desde a sangria até o abate do animal, nas feiras livres, nos açougues e supermercados, com o agravante de que durante todo o processamento, é manipulada por pessoas que, por falta de orientação ou negligência, colaboram para a baixa qualidade do produto que chega ao consumidor (OLIVEIRA et al., 2002; FAUSTINO et al., 2003; PIGATTO; BARROS, 2003).

Diante do exposto, podemos observar que o consumo de carne de baixa qualidade pode representar riscos ao consumidor, tais como zoonoses, toxinfecções e intoxicações alimentares por microorganismos. Deve-se avaliar a importância da inspeção veterinária antes, durante e após o abate dos animais como condição impositiva para reduzir ao mínimo 
as ocorrências que influem na qualidade e na sanidade da carne (PARDI et al., 2001).

WALTZ et al. (2007), estudando a importância da inspeção final na qualidade da carne, concluíram que esta prática tem grande valor no controle das patologias, mostrando-se rigorosa na segurança alimentar.

Este tipo de abate realizado em local inapropriado é um sério problema urbano contemporâneo, que está relacionado a fatores de natureza sócio-econômica e apresenta reflexos na comunidade por causa das péssimas condições higiênicas e sanitárias dos alimentos produzidos, poluição do meio ambiente e propagação de patógenos, representando, portanto, um sério risco para a saúde coletiva.

\section{CONSIDERAÇÃOES FINAIS}

O presente trabalho concluiu que não existe nenhuma condição mínima higiênicas-sanitárias presentes no local além de condições físicas inexistentes para a finalidade que se destinam, pondo em risco a saúde do manipulador e a saúde da população, pela exposição a agentes infecciosos e parasitários, como aqueles que são transmitidos ao homem pelos animais, pela ingestão de alimentos de qualidade sanitária suspeita e pela contaminação do meio ambiente.

Visto que o abate clandestino ainda é um problema presente em nosso país, cabe à população procurar saber a origem dos produtos comprados e denunciar os locais que realizam essa prática, assim como os comércios que disponibilizam os produtos para venda. Além disso, o papel domunicípio, através da vigilância sanitária é fundamental no combate ao abate ilegal, mas, infelizmente os órgãos públicos e produtores dão pouca importância a esta prática criminosa que agride a saúde humana e desrespeita os consumidores já que ela se configura como um problema social.

\section{REFERÊNCIAS}

BÁNKUTI, F.I.; AZEVEDO; P.F. Abates clandestinos de bovinos: uma análise das características do ambiente institucional. In: XXXIX SOBER - Congresso Brasileiro de Economia e Sociologia Rural. Anais XXXIX Congresso Brasileiro de Economia e Sociologia Rural. Recife: SOBER, 2001.

BARBOSA FILHO, J.A.D; SILVA, I.J.O. Abate humanitário: ponto fundamental do bemestar animal. Revista Nacional da Carne, São Paulo, v. 28, n. ju, p. 36-44, 2004. 
BATISTA, C.S.A.; AZEVEDO, S.S.; ALVES, C.; VASCONCELLOS, S.A.; MORAIS, Z.M.; CLEMENTINO, I.J.; LIMA, F.S.; ARAUJO NETO, J.O. Soroprevalência de leptospirose em cães errantes da cidade de Patos, Estado da Paraíba, Brasil. Brazilian Journal of Veterinary Research and Animal Science, v. 41, n. 2, p. 131-136, 2004.

BRASIL. Ministério da Agricultura. Decreto $n^{\circ}$ 30.691de 29/03/1952 e alterado pela última vez pelo Decreto ${ }^{\circ}$ 6.385, de 27 de fevereiro de 2008. Regulamento da inspeção industrial e sanitária de produtos de origem animal - RIISPOA. Diário Oficial da União, 2008.

COSTA, P.C.; RODRIGUES, P.R.; GURGEL, M.P.L. Abate clandestino - riscos e consequências. In: X SECOMV, UFES, Alegre, Espírito Santo, 2011.

DAlla COSTA, O.A.; ARAUJO, A.P.; BAGGIO, E.; CIOCCA, J.; ATHAYDE, N.; SCHNEIDER, D. Importância do jejum no manejo pré-abate de suínos. Concórdia: Embrapa Suínos e Aves. Instrução Técnica para o Suinocultor. 1. ed. p. 2, 2007.

DUKE, G.E.; BASHA, M.; NOLL, S. Optimum duration of feed and water removal prior to processing in order to reduce the potential for fecal contamination in turkeys. Poultry Science, v. 76, n. 3, p. 516-522, 1997.

FREITAS, J.A.; GALINDO, G.A.R.; SARRAF, K.A.; OLIVEIRA, J.P.; RAMOS, O.S.; HERRERA, D.E.S.; SANTOS, E.J.C. Situação atual e aspectos higiênicos e sanitários do abate clandestino, na região metropolitana de Belém, Pará. Higiene Alimentar, v. 20, n. 143, p. 45-49, 2006.

IBGE (Instituto Brasileiro de Geografia e Estatística). Estatística da Produção Pecuária. jan - mar. 2018.

LIMA, L.R.; BARBOSA FILHO, J.A.D. Impacto do manejo pré-abate no bem-estar de caprinos e ovinos. Journal of Animal Behaviour and Biometeorology, v. 1, n. 2, p. 52-60, 2013. 
LIMA, M.C.F. Principais zoonoses em pequenos animais: breve revisão. Veterinária e Zootecnia, v. 24, n. 1, p. 84-106, 2017.

MAPA - Ministério da Agricultura, Pecuária e Abastecimento, 2013. Disponível em: http://www.agricultura.gov.br/animal/especies/bovinos-ebubalinos. Acesso em: 25 jun. 2019.

NORTHCUTT, J.K.; SAVAGE, S.I.; VEST, L.R. Relationship between feed Withdrawal and viscera condition of broilers. Poultry Science, v. 76, p. 410-414, 1997.

OLIVEIRA, N.M.S.; NASCIMENTO, L.C.; FIORINI, J.E. Isolamento e identificação de bactérias facultativas mesofílicas em carnes frescas bovinas e suínas. Higiene Alimentar, São Paulo, v. 16, n. 91, p. 68-74, 2002.

PARDI, M.C; SANTOS, I.F.; SOUZA, E.R.; PARDI, H.S. Ciência, higiene e tecnologia da carne. 2. ed. Goiânia: Editora UFG, 2001. v. 1.

PEREIRA, A.S.C.; LOPES, M.R.F. Manejo pré-abate e qualidade da carne. 6 p. 2006. Disponível em: http://www.carneangus.org.br. Acesso em: 28 jun. 2019.

PIGATTO, C.P.; BARROS, A.R. Qualidade da carne moída bovina resfriada, comercializada em açougues da região de Curitiba. Higiene Alimentar, São Paulo, v. 17, n. 108, p. 53-57, 2003.

ROÇA, R.O. Abate humanitário de bovinos. Revista de Educação Continuada, v. 4, n. 2, p. 73-85, 2001.

ROUQUAYROL, M.Z.; ALMEIDA FILHO, N. Epidemiologia e saúde. 6. ed. Rio de Janeiro: Medsi, 708p. 2003.

SAVAGE, S. A practical look at its effect on intestine emptying, contamination and yield. 1998. Disponível em: http://www.gov.mb.ca/agriculture/livestock/ poultry/bba01s26.html. Acesso em: 01 jul. 2019. 
SCHETTINO, D.N.; CANÇADO, S.V.; BAIÃO, N.C.; LARA, L.J.C.; FIGUEIREDO, T.C.; SANTOS, W.L.M. Efeito do período de jejum pré-abate sobre o rendimento de carcaça de frango de corte. Arquivo Brasileiro de Medicina Veterinária e Zootecnia, v. 58, n. 5, p. 918-924, 2006.

SCHOENHALS, M. Avaliação da eficiência do processo de flotação aplicado ao tratamento primário de efluentes de abatedouro avícola Florianópolis - SC. 2006. 99f. Dissertação (Mestrado em Engenharia Química) - Universidade Federal de Santa Catarina, Florianópolis, 2006. Disponível em: http://www2.enq.ufsc.br/teses/m152.pdf. Acesso em: 01 jul. 2019.

STOLKER, A.A.M.; BRINKMAN, U.A.T. Analytical strategies for residue analysis of veterinary drugs and growth-promoting agents in food producing animals: a review. Journal of Chromatography A. Amsterdam, v. 1067, p. 15-53, 2005.

TAVOLARO, P.; PEREIRA, I.M.T.B.; PELICIONI, M.C.F.; OLIVEIRA, C.A.F. Empowerment como forma de prevenção de problemas de saúde em trabalhadores de abatedouros. Revista de Saúde Pública, v. 41, n. 2, p. 307-312, 2007.

TERRA, N.N.; FRIES, L.L.M. A qualidade da carne suína e sua industrialização. In: Conferência Virtual Internacional sobre Qualidade de Carne Suína, v.1, Informe Técnico EMBRAPA. Rio Grande do Sul: Universidade Federal de Santa Maria, p.1-5. 2000.

VRAGOVIC, N.; BAZULIC, D.; NJARI, B. Risk assessment of streptomycin and tetracycline residues in meat and milk. Food and Chemical Toxicology, v. 49, p. 352-355, 2011.

WALTZ, E.; CORTEZ, N.M.S.; CORTEZ, M.A.S. Importância do departamento de inspeção final na qualidade da carne. Higiene Alimentar, v. 21, n. 150, p. 104-105, 2007. 